\title{
CVD of Solid Oxides in Porous Substrates for Ceramic Membrane Modification
}

\author{
Y. S. Lin and A. J. Burggraaf \\ Laboratory of Inorganic Chemistry, Materials Science and Catalysis, \\ Dept. of Chemical Technology, University of Twente, 7500 AE Enschede, The Netherlands
}

The deposition of yttria-doped zirconia has been experimented systematically in various types of porous ceramic substrates by a modified chemical vapor deposition $(C V D)$ process operating in an opposing reactant geometry using water vapor and corresponding metal chloride vapors as reactants. The effects of substrate pore dimension and structure, bulk-phase reactant concentration, reactant diffusivity in substrate pores and deposition temperature are experimentally studied and explained qualitatively by a theoretical modeling analysis. The experimental and theoretical results suggest a reaction mechanism which depends on water vapor and chloride vapor concentrations. Consequently, the diffusivity, bulk-phase reactant concentration, and substrate pore dimension are important in the CVD process. Effects of deposition temperature on the deposition results and narrow deposition zone compared to the substrate thickness also suggest a Langmuir-Hinshelwood reaction mechanism involved in the CVD process with a very fast CVD reaction rate. Gas permeation data indicate that whether deposition of solid in substrate pores could result in the pore-size reduction depends strongly on the initial pore-size distribution of the substrate.

\section{Introduction}

Ceramic membranes are gaining technical importance in chemical industries, because they have many unique characteristics, such as good thermal and structural stability and capability to have catalytic properties. Applications of ceramic membranes in separation and catalytic reaction require a thin membrane layer with a good selectivity and a high permeability for desired species. The thin ceramic membrane layer is usually supported by a highly porous ceramic to obtain sufficient mechanical strength. Good selectivity and high permeability of a ceramic membrane layer can be generally achieved by reducing the pore size and the thickness of the membrane layer. Supported ceramic membrane layers with an average pore diameter and a thickness of about $5 \mathrm{~nm}$ and $5 \mu \mathrm{m}$, respectively, can be made by several methods (Burggraaf and Keizer, 1991; Hsieh, 1988). Nevertheless, it is still difficult to prepare ceramic membrane layers with a pore diameter less than $3 \mathrm{~nm}$. Recently, the extension of chemical vapor deposition (CVD) into porous

Correspondence concerning this article should be addressed to $Y$. S. Lin, who is currently at the Department of Chemical Engineering, ML 171, University of Cincinnati, Cincinnati, OH 45221 . substrates (Carolan and Michaels, 1987; Lin et al., 1989a, 1990a; Gavalas et al., 1989; Okubo and Inoue, 1989) has demonstrated several possibilities of using CVD techniques for the preparation of membrane composites having a porous membrane layer of subnanometer pore diameter or dense membrane layer. Among these vapor-phase methods, a modified CVD process appears to be the most promising technique for ceramic membrane preparation or modification.

The modified CVD process for membrane preparation or modification is operated in an opposing reactant geometry. A porous substrate disk (or tube) separates a CVD reactor into two chambers, one of which is filled with an oxygen source reactant and the other with a metal source reactant. During the modified CVD process, the two gas reactants (for example, $\mathrm{ZrCl}_{4}$ vapor and water vapor) from the two reactor chambers interdiffuse into the porous substrate and react to form a corresponding solid product (for example, $\mathrm{ZrO}_{2}$ ) which is deposited in the internal pore surface of the substrate. The substrate can be a coarse pore ceramic (for membrane preparation) (Lin et al., 1989a; Gavalas et al., 1989; Nam and Gavalas, 
1989) or, in principle, a two-layer ceramic membrane composite prepared by other methods, which will be demonstrated in this article. The aims of developing this modified CVD process for ceramic membrane preparation or modification are twofold: (1) to deposit a thin film spreading over the internal pore surface in a desired region across the membrane substrate to modify the pore surface chemistry of the substrate (membrane); (2) to deposit the solid product in a small zone across the substrate to form a thin porous layer with a reduced pore size in (or on) the substrate (as support). This modified CVD process is also the initial stage of an important electrochemical vapor deposition (EVD) process for making thin, dense, solid electrolyte films on porous substrates (Isenburg, 1977; Carolan and Michaels, 1990; Pal and Singhal, 1990; Lin et al., 1990b).

Since the modified CVD method for membrane preparation or modification is rather new, very limited studies have been reported on the understanding of such an interesting CVD process. Carolan and Michaels (1987) reported the deposition of yttria/zirconia in porous substrate by the modified CVD process for the purpose of growing dense yttria stabilized zirconia films by the subsequent EVD process. A mixture of water vapor/hydrogen and a mixture of $\mathrm{YCl}_{3} / \mathrm{ZrCl}_{4}$ vapors were used as the oxygen source reactant and the metal source reactant, respectively. As substrates, they used in their studies one-layer porous alumina disks of $30 \mu \mathrm{m}$ in pore diameter as well as two-layer composite disks consisting of a top layer and a support with a pore diameter of $1 \mu \mathrm{m}$ and $30 \mu \mathrm{m}$, respectively. Zirconia and yttria were found to be deposited mainly in substrate, penetrating to a distance that corresponds to no more than 2 to 3 times pore diameter. Similar experimental results were also reported by Lin et al. (1989a) on deposition of zirconia and yttria in porous alumina disks of about $0.2 \mu \mathrm{m}$ in pore diameter. Gavalas et al. (1989) studied the deposition of thin films of amorphous silica inside the porous wall of a Vycor glass tube by the modified CVD using silane and oxygen as the two reactants. Although the potential for using the CVD technique for membrane preparation or modification with substrates of relative large pores has been demonstrated in these studies, the effects of process parameters and experimental conditions on the deposition results have not been investigated for this interesting CVD process. Deposition in composite membrane substrates with a very thin $(\leq 6 \mu \mathrm{m})$ and small-pore ( $\leq 20 \mathrm{~nm}$ ) top layer has not been reported before the present work.

To gain a better insight into this modified CVD process from experimental viewpoint, we have recently carried out a systematic experimental investigation on the effects of different process parameters and experimental conditions on the deposition of zirconia and yttria by the modified CVD process in various types of porous substrate having different pore sizes. Some preliminary experimental results on coarse pore substrates (pore diameter larger than $0.1 \mu \mathrm{m}$ ) were recently reported by Lin et al. (1990a). In this article, we present experimental results of the more systematic investigation and the explanation of the experimental findings using the results of a recently developed theoretical modeling analysis (Lin and Burggraaf, 1991b). In this study, emphasis has been given on the deposition of zirconia and yttria in supported membrane top layers with a small pore diameter $(\leq 20 \mathrm{~nm})$ and thickness ( 3 or $6 \mu \mathrm{m}$ ). The codeposition of small amount of yttria with

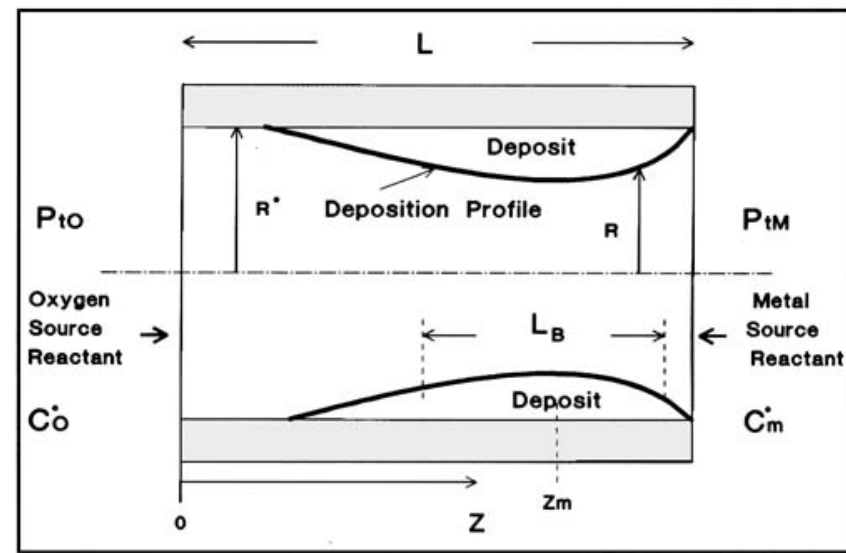

Figure 1. Cylindrical pore model showing the deposition profile in substrate pore during the modified CVD process.

zirconia is mainly for the growth of yttria-stabilized zirconia thin films by the subsequent EVD process after poreclosure. Nevertheless, the main deposition product is zirconia (most time $>90 \%$ ), and therefore we present the CVD results as of only deposition of zirconia from zirconium chloride and water vapors to facilitate the discussion.

\section{Results of Theoretical Analysis}

The modified CVD process has been theoretically investigated by Carolan and Michaels (1987) with a simple cylindrical pore model and Lin et al. (1989b) with an improved cylindrical pore model. Their theoretical analysis was consistent with some of the experimental findings but failed to explain other experimental results (Lin et al., 1990a), possibly because of the use of some improper boundary conditions in the models. Lin and Burggraaf (1991b) recently reported a more comprehensive analysis of the modified CVD process using a mathematical model that takes into account intrapore diffusion, viscous flow, chemical reaction and change of substrate pores during deposition. We will summarize some results from the previous theoretical analysis in a qualitative or semiquantitative way so that the theoretical results can be directly used to explain the experimental findings reported here.

The deposition profile is the distribution of solid deposit across a ceramic substrate after a given period of deposition time. If the cylindrical pore model is used, the deposition profile can be expressed as the local pore radius of a substrate pore as a function of the pore axial distance at a certain deposition time, as depicted in Figure 1. In a substrate pore with initially a constant pore radius, a smaller local radius in the deposition profile means a larger quantity of solid deposited at that location. Simulated deposition profiles provide information on the following three quantities that are important to ceramic membrane preparation or modification (see Figure 1): (1) maximum deposition location $Z_{m}$ which corresponds to the location of minimum pore radius of a deposition profile; (2) width of deposition zone $L_{B}$, defined roughly as the average width of the deposition profile; and (3) the average maximum pore narrowing rate $q$ (defined as $q=-\Delta R / \Delta t$ at $Z=Z_{m}$ ). A controlled width of the deposition zone is desired for modifying the pore surface chemistry of a membrane. However, to deposit 
a porous membrane layer, the width of deposition zone should be as small as possible to minimize the average layer thickness. The deposition rate is important for the control of the CVD process. The maximum deposition location indicates the position of membrane layer formed in (or on) a porous support (which is the substrate during the deposition).

The simulation results show that the distribution of solid deposit (such as $\mathrm{ZrO}_{2}$ ) across a porous substrate (the deposition profile) and the deposition rate are determined mainly by reaction orders with respect to the two reactants, modified Thiele modulus $\Phi$, concentration ratio $\beta$, diffusivity ratio $\lambda_{M}$, and pressure drop coefficient $\alpha$ defined as follows:

$$
\begin{gathered}
\Phi=K L^{2}\left[C_{m}^{a}\right]^{N-1}\left[C_{O}^{o}\right]^{M} / D_{m}^{o} R^{o} \\
\beta=C_{\bigcirc}^{o} / C_{m}^{o} \\
\lambda_{M}=D_{O}^{o} / D_{m}^{o} \\
\alpha=\left(P_{t M}^{2}-P_{t \circ}{ }^{2}\right) / P_{t O}{ }^{2}
\end{gathered}
$$

With subscript $m$ for the metal source reactant (such as $\mathrm{ZrCl}_{4}$ ) and $\mathrm{O}$ for the oxygen source reactant (such as water vapor), the parameters in the above equations are identified as (referred to Figure 1): $N$ and $M$ are the reaction orders with respect to the metal source reactant and the oxygen source reactant, respectively; $K$, the reaction rate constant; $L$, the thickness of substrate disk; $C^{o}$, the concentration of reactant vapor in the reactor chamber (not in the substrate pore); $D^{\circ}$, the effective diffusivity of reactant vapor in the substrate pore; $R^{o}$, the average pore radius of substrate; $P_{I M}$ and $P_{H O}$, the total pressures at the metal source reactant side and the oxygen source reactant side, respectively.

The simulation results show that many parameters can affect the maximum deposition location. For the CVD reaction with a zero reaction order with respect to one reactant, the maximum deposition is always located at the surface of a substrate disk exposed to the other reactant with a nonzero reaction order, unless there is insufficient amount of the reactant with zero reaction order for consumption. For example, the maximum amount of the deposited $\mathrm{ZrO}_{2}$ is found at the substrate surface exposed to $\mathrm{ZrCl}_{4}$ vapor if the reaction order with respect to water vapor is zero, provided there is sufficient water vapor for consumption, which is generally true for the studied CVD process. In this case, the amount of deposited $\mathrm{ZrO}_{2}$ decreases gradually across the substrate toward the water side. However, for the cases with nonzero reaction order with respect to both reactants, the maximum deposition location can be at any location from the substrate surface to the middle of a substrate, depending mainly on the diffusivity ratio, the reactant concentration ratio, and the pressure drop coefficient. In these cases, if the diffusivity ratio or the concentration ratio is close to the ratio of the stoichiometric coefficient of the oxygen source reactant to that of the metal source reactant, the maximum deposition location is usually at the middle of a substrate. When the intrapore diffusivity or bulk-phase concentration of one of the reactants is larger than that of the other reactant, the maximum deposition location can be near or at the substrate surface exposed to the reactant with a smaller diffusivity or lower bulk-phase concentration.

The total pressure drop can affect the maximum deposition location only under the conditions that a parameter $\lambda_{v}$ defined as follows is larger than a certain value:

$$
\lambda_{v}=\left(R^{o}\right)^{2} P_{\mathrm{av}} \epsilon / 16 \mu \tau D_{m}^{o}
$$

where $P_{\mathrm{av}}$ is the average total pressure [ $\left.\left(P_{t M}+P_{t \mathrm{O}}\right) / 2\right], \epsilon$ and $\tau$ are the porosity and tortuosity factor of the substrate, and $\mu$ is the viscosity of the carrier gas. It is found that when $\lambda_{v}$ is smaller than 0.01 , a total pressure drop essentially does not change the maximum deposition location. Otherwise, increasing the total pressure drop will move the maximum deposition location toward the lower total pressure side. Obviously, a modified CVD process, under the conditions of a small substrate pore size, high temperature, and low average total pressure, is generally characterized by a very small value of $\lambda_{v}$, and consequently, the total pressure drop has negligible effects.

The modified Thiele modulus $\Phi$ affects mainly the width of deposition zone and the pore narrowing rate. A smaller value of $\Phi$ results (at constant $L^{2} / D_{m}^{o}$ ) in a wider deposition zone with a smaller pore narrowing rate. As indicated by Eq. 1, the modified Thiele modulus is related to the ratio of the reaction rate to the diffusion rate. In the Knudsen diffusion regime, the effective diffusivity is proportional to the pore radius. So, as can be seen from the definition, $\Phi$ is proportional to $\left(L / R^{\circ}\right)^{2}$. Therefore, the deposition zone in a substrate with a larger thickness and/or small pore size is more likely to be very narrow with respect to the substrate thickness. $\Phi$ may also vary with temperature, but in a more complicated way, depending on the temperature dependence of the reaction rate constant $K$ and the effective diffusivity $D_{m}^{o}$. It should be pointed out that the reaction rate constant $K$ in Eq. 1 is the "apparent" reaction rate constant which lumps up all the rate or equilibrium constants in the different steps involved in the reaction/ deposition mechanism. Therefore, $K$ may decrease or increase with the deposition temperature. Since a higher temperature always results in a larger diffusivity, a negative temperature dependency of the modified Thiele modulus is possible, depending on the reaction/deposition mechanism of the modified CVD reaction. Furthermore, increasing the bulk-phase concentrations of both reactants can also narrow the width of a deposition zone as a result of the increase in the modified Thiele modulus.

For a CVD reaction with zero reaction order with respect to the oxygen source reactant, the maximum pore change rate at $Z=L$ is:

$$
d R / d t=-V_{m} K\left(C_{m}^{o}\right)^{N}
$$

where $V_{m}$ is the molar volume of the solid deposit. Integrating Eq. 6 from $R=R^{\circ}$ to $R=0$ gives the pore closure time:

$$
t_{p c}=R^{o} / V_{m} K\left(C_{m}^{o}\right)^{N}
$$

In this case, the pore narrowing rate depends only on the reaction rate, and the pore closure time is proportional to the substrate pore size.

For a CVD reaction with a nonzero reaction order with respect to both reactants, other parameters in addition to the modified Thiele modulus can affect the pore narrowing rate. It is generally true that a modified CVD process with a narrower deposition zone has a higher pore narrowing rate. A value of 


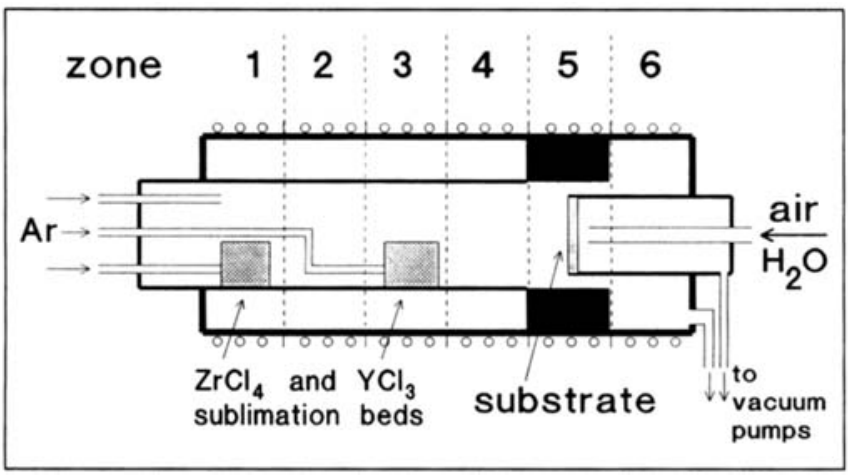

Figure 2. Central reactor part of the CVD apparatus.

$\lambda_{M}$ or $\beta$ more close to the ratio of the stoichiometric coefficient of the oxygen source reactant to that of the metal source reactant gives a wider deposition zone (with the maximum deposition located inside substrate) and a slower pore narrowing rate (or longer pore closure time). This kind of effects of $\lambda_{M}$ or $\beta$ on the pore narrowing rate is found to be more significant when the modified Thiele modulus is large. Finally, it is generally true that the larger the diffusion resistance for a substrate (larger ratio of the thickness to the pore size), the smaller the pore narrowing rate.

\section{Experimental Studies}

The CVD experiments were performed in a home-built CVD apparatus, which consisted of a reactor, a vacuum system, a metal chloride delivery system, and an oxygen source delivery system. The detailed schematic diagram and description of the apparatus are given elsewhere (de Haart et al., 1991). The central part of the CVD apparatus was a reactor made of three dense alumina tubes placed in a six-zone furnace, as shown in Figure 2. A porous substrate disk was sealed on the end of the smallest tube with an Aremco cement, dividing the reactor into two chambers. The oxygen source reactant was introduced into the smallest tube (the oxygen chamber). The metal chloride vapor was generated in the medium tube (the chloride chamber) by passing Ar streams [at a total flow rate of $27.5 \mathrm{~mL}$ (Stp.)/min] through the sublimation beds filled with $\mathrm{ZrCl}_{4}$ (and $\mathrm{YCl}_{3}$ ) powders.

Alumina membrane substrates consisting of an $\alpha$-alumina support with coarse pores and a La-doped $\gamma$-alumina top layer were prepared by the sol-gel method (Lin and Burggraaf, 1991a). The membrane top layers, with different thicknesses and pore sizes, have an improved thermal and chemical stability and a rather uniform pore-size distribution (Lin and Burggraaf, 1991a). To investigate the effects of substrate pore dimension and structure on the deposition results, two other types of substrate with a larger pore size were also used in the CVD experiments: $\alpha$-alumina disks with coarse pores and ceramic composites consisting of a large-pore $\alpha$-alumina disk coated with a thin layer of porous Sr-La-Mn oxide. All substrate disks were $12 \mathrm{~mm}$ in diameter and 1-2 $\mathrm{mm}$ in thickness. Characteristics and pore dimensions of the three types of substrates are listed in Table 1. For the membrane and composite substrates, a substrate disk was cemented on the smallest reactor tube with its thin layer facing to the chloride chamber.

A mixture of $\mathrm{ZrCl}_{4}$ and $\mathrm{YCl}_{3}$ vapors (typical molar ratio, 10:1) and, for most deposition runs, a mixture of water vapor and air (typical molar ratio, 1:1) were used as the two gas reactants. As mentioned in the Introduction section, another important objective for the present CVD experiments was to grow a thin dense film of yttria-stabilized zirconia by the subsequent EVD process after pore closure. The addition of $\mathrm{YCl}_{3}$ vapor in $\mathrm{ZrCl}_{4}$ vapor for the deposition of yttria-doped zirconia and the use of air as the carrier gas for water vapor in most runs are mainly for this objective. Preliminary experimental results showed that with pure oxygen or dried air as the oxygen source reactant, negligible deposition of the solid oxides was observed within two hours of the deposition in the CVD process. Therefore, the use of air as the carrier gas for water vapor has negligible effects on the deposition results before the substrate pore is closed. The main CVD reaction (over 90\%) involved in the CVD process was:

$$
\mathrm{ZrCl}_{4}(\mathrm{~g})+2 \mathrm{H}_{2} \mathrm{O}(\mathrm{g})=\mathrm{ZrO}_{2}(\mathrm{~s})+4 \mathrm{HCl}(\mathrm{g})
$$

Before a CVD experiment, the oxygen chamber of the CVD reactor was flushed with Ar for an extended period of time. The CVD experiment was started by introducing water vapor/air stream into the water chamber [at the carrier gas flow rate of $3.5 \mathrm{~mL}(\mathrm{Stp}.) / \mathrm{min}]$. After a given period of deposition, the CVD experiment was terminated by switching off the water vapor/air stream followed by flushing the oxygen chamber with Ar stream. The typical experimental conditions for the CVD experiments are summarized in Table 2. After

Table 1. Characteristics of Substrates and Typical Pore Closure Time Obtained by Deposition of Yttria-Doped Zirconia

\begin{tabular}{|c|c|c|c|c|c|}
\hline \multirow{2}{*}{$\begin{array}{l}\text { Substrate } \\
\text { Structure }\end{array}$} & \multicolumn{2}{|c|}{ Membrane } & \multirow{3}{*}{$\begin{array}{l}\text { Coarse Pore } \\
\text { One Layer } \\
\alpha \text {-Alumina }\end{array}$} & \multicolumn{2}{|c|}{ Composite } \\
\hline & Support & Top Layer & & Support & Top Layer \\
\hline Material & $\alpha$-Alumina & $\begin{array}{l}\text { La-Doped } \\
\gamma \text {-Alumina }\end{array}$ & & $\alpha$-Alumina & $\begin{array}{l}\text { Sr-La-Mn } \\
\text { Oxide }\end{array}$ \\
\hline $\begin{array}{l}\text { Avg. Pore } \\
\text { Radius, } R^{o}\end{array}$ & $0.08 \mu \mathrm{m}$ & $5 / 10 \mathrm{~nm}^{+}$ & $0.08 \mu \mathrm{m}$ & $5 \mu \mathrm{m}$ & $0.2 \mu \mathrm{m}$ \\
\hline Thickness, $L$ & $2 \mathrm{~mm}$ & $3 / 6 \mu \mathrm{m}$ & $2 \mathrm{~mm}$ & $1 \mathrm{~mm}$ & $35 \mu \mathrm{m}$ \\
\hline $\begin{array}{l}\left(F_{0} / L\right) \times 10^{6} \\
\left(\mathrm{~mol} / \mathrm{m}^{2} \cdot \mathrm{s} \cdot \mathrm{Pa}\right)^{*}\end{array}$ & \multicolumn{2}{|c|}{3.5} & 4.1 & \multicolumn{2}{|c|}{14.4} \\
\hline $\begin{array}{l}\text { Pore-Closure } \\
\text { Time, } t_{p c}(\min )^{* *}\end{array}$ & \multicolumn{2}{|c|}{$<10$} & 45 & \multicolumn{2}{|c|}{30} \\
\hline
\end{tabular}

\footnotetext{
* Ar permeability measured in CVD apparatus at $1,000^{\circ} \mathrm{C}$ before deposition.

** Under the deposition conditions in Table 2. The membrane substrates have a top layer with $L=3 \mu \mathrm{m}$ and $R^{\circ}=10 \mathrm{~nm}$.

${ }^{+}$From nitrogen desorption isotherm based on cylindrical pore model.
} 
Table 2. Typical Experimental Conditions for the CVD Experiments

\begin{tabular}{lc}
\hline $\mathrm{ZrCl}_{4}$ Vapor Conc. & $C_{m}^{o} \approx 2.0 \times 10^{-9} \mathrm{~mol} / \mathrm{mL}$ \\
Water Vapor Conc. & $C_{\mathrm{O}}^{o} \approx 3.5 \times 10^{-9} \mathrm{~mol} / \mathrm{mL}$ \\
Total Pressure & $P_{r O}=P_{t M}=2 \mathrm{mbar}$ \\
Deposition Temp. & $T_{\mathrm{dep}}=1,000^{\circ} \mathrm{C}$ \\
Sublimation Bed Temp. & $T_{\mathrm{ZrCl}_{4}}=160^{\circ} \mathrm{C}$ \\
Diffusivity for Water Vapor* & $D_{\mathrm{O}}^{o}=0.16 \mathrm{~cm}^{2} / \mathrm{s}$ \\
Diffusivity for Oxygen & $D_{\mathrm{O}}^{*}=0.12 \mathrm{~cm}^{2} / \mathrm{s}$ \\
Diffusivity for $\mathrm{ZrCl}_{4}$ Vapor* & $D_{m}^{o}=0.045 \mathrm{~cm}^{2} / \mathrm{s}$ \\
Deposit $\left(\mathrm{ZrO}_{2}\right)$ Molar Vol. $^{2}$ & $V_{M}=21.5 \mathrm{~mL} / \mathrm{mol}$ \\
\hline
\end{tabular}

- For coarse pore substrate with $t=2$ and $\epsilon=0.5$.

deposition, the substrate was taken out of the CVD reactor, and the cross-section of some of the substrates was analyzed by scanning electronic microscopy (SEM), energy-dispersive spectrometry (EDS), and secondary ion mass spectrometry (SIMS) to examine the deposit distribution across the substrates.

For some deposition runs on the coarse pore substrates, an in-situ gas permeation method was used to monitor the pore narrowing process (due to the deposition of $\mathrm{ZrO}_{2}$ in substrate pores) during the CVD process. After about $10-15$ min interval for the deposition, the CVD process was interrupted by switching off the water vapor/air stream, and the reactor chambers were slowly filled with Ar to 200 mbar for the chloride chamber $(8,030 \mathrm{~mL}$ in volume) and $100 \mathrm{mbar}$ for the oxygen chamber ( $375 \mathrm{~mL}$ in volume). The pressure increase in the oxygen chamber due to Ar permeation from the chloride chamber was measured at a substrate temperature the same as for the deposition. For some deposition runs, the pore-closure time was roughly measured by the in-situ Ar permeation data through the substrate. Details on the experimental conditions, experimental procedure, and sample characterization are given by de Haart et al. (1991).

More accurate permeation measurements were performed on most samples before deposition and after a given deposition time (without interruption) by a home-made permeation apparatus at room temperature with helium as the permeating

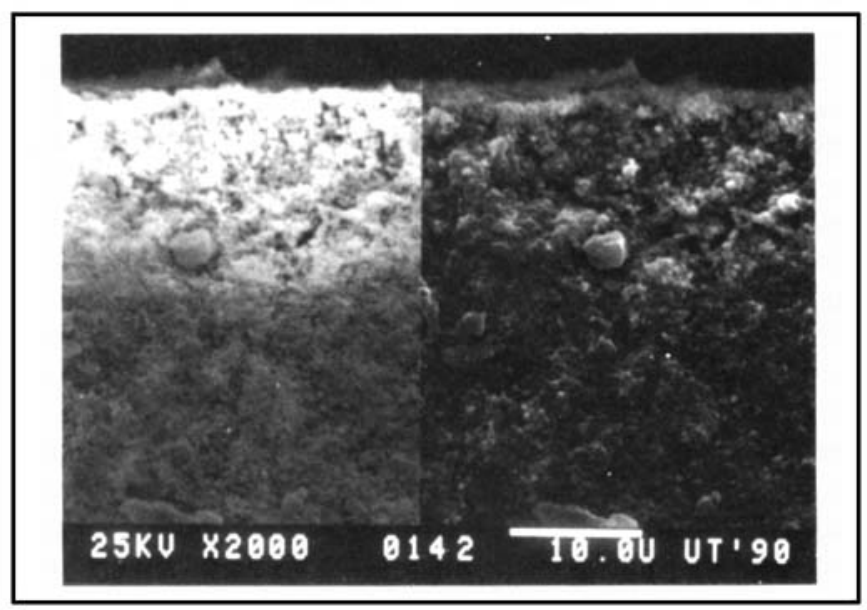

Figure 3. SEM photo showing the deposit distribution across a coarse pore substrate.

The top side of substrate was exposed to metal chloride vapor. Righthand side is SEI (morphology); lefthand side is BEI (composition: darkness $=\mathrm{Al}$; brightness $=\mathrm{Zr}$ ) (bar shown in the SEM is $10 \mu \mathrm{m})$. gas. In measuring permeability, He flow at a constant flow rate $Q[0.1-1.0 \mathrm{~mL}(\mathrm{Stp}.) / \mathrm{s}]$ was passed through the substrate disk with a permeation area of $S\left(0.5 \mathrm{~cm}^{2}\right)$. After a steady state was reached, the higher pressure in the upstream side, $P_{h}$, and the low pressure in the downstream side, $P_{l}$, were measured. The permeability was calculated by $(F / L)=Q / S\left(P_{h}-P_{l}\right)$. For each substrate before or after deposition, He permeability at different average pressure $P_{\mathrm{av}}\left[P_{\mathrm{av}}=\left(P_{h}+P_{l}\right) / 2\right]$ across a disk was measured and correlated to the following linear relation describing the permeability of pure nonadsorbable gas through a homogeneous porous disk (Keizer et al., 1988; Lin and Burggraaf, 1991a):

$$
(F / L)=\alpha^{\prime}+\beta^{\prime} \cdot P_{\mathrm{av}}
$$

The permeability coefficients $\alpha^{\prime}$ and $\beta^{\prime}$ are contributed by the Knudsen and the viscous flows, respectively as:

$$
\alpha^{\prime}=1.06(1 / L)(\epsilon / \tau) R^{o}\left(R_{g} T M_{g}\right)^{-1 / 2}
$$

and

$$
\beta^{\prime}=0.125(1 / L)(\epsilon / \tau)\left(R^{o}\right)^{2} / \mu R T
$$

where $T$ is the temperature, $M_{g}$ and $\mu$ are the molecular weight and viscosity of the permeating gas, respectively, and $R_{\mathrm{g}}$ is the gas constant. The permeability ratio, defined as the ratio of the permeability coefficient $\alpha^{\prime}$ for a substrate after a period of deposition to that before deposition, is used to indicate the extent of pore narrowing. For a given deposition time, the smaller the permeability ratio, the larger the pore narrowing rate. It should be pointed out that $R^{\circ}$ in Eqs. 9 and 10 is the average pore radius, although in practice any substrate may have a pore-size distribution.

\section{Results and Discussion \\ Deposit distribution across substrate}

Zirconia was found inside all three types of substrates after a period of deposition. The pores of the substrates become plugged by the deposit after about 5-45-min deposition, depending on the substrate type and experimental conditions. The moment of pore closure was indicated by the $\mathrm{Ar}$ or $\mathrm{He}$ permeability being at least 200 times smaller than the initial permeability. For the membrane and composite substrates, all the deposited zirconia was found in top layers of the substrate (note that the top layer was faced to chloride side during deposition). Figure 3 shows typical SEM photos of a backscattering electron image (BEI) and a secondary electron image (SEI) for one of the coarse pore substrates after about 45-min deposition. The brightness in the BEI corresponds to the amount of $\mathrm{ZrO}_{2}$ with $\mathrm{Al}_{2} \mathrm{O}_{3}$ as the background. The amount of deposited $\mathrm{ZrO}_{2}$ gradually decreases across the substrate and becomes negligible in the substrate pores about $10-20 \mu \mathrm{m}$ deep from chloride side.

This kind of deposit distribution was confirmed by the EDS analysis, as given in Figure 4a. The penetration depth of zirconia measured by SIMS (Figure 4b) seems to be much deeper than that by EDS (Figure 4a). This difference is probably due to the fact that SIMS detects much more shallow surface profile on substrate grain surface than EDS so that very small amounts 

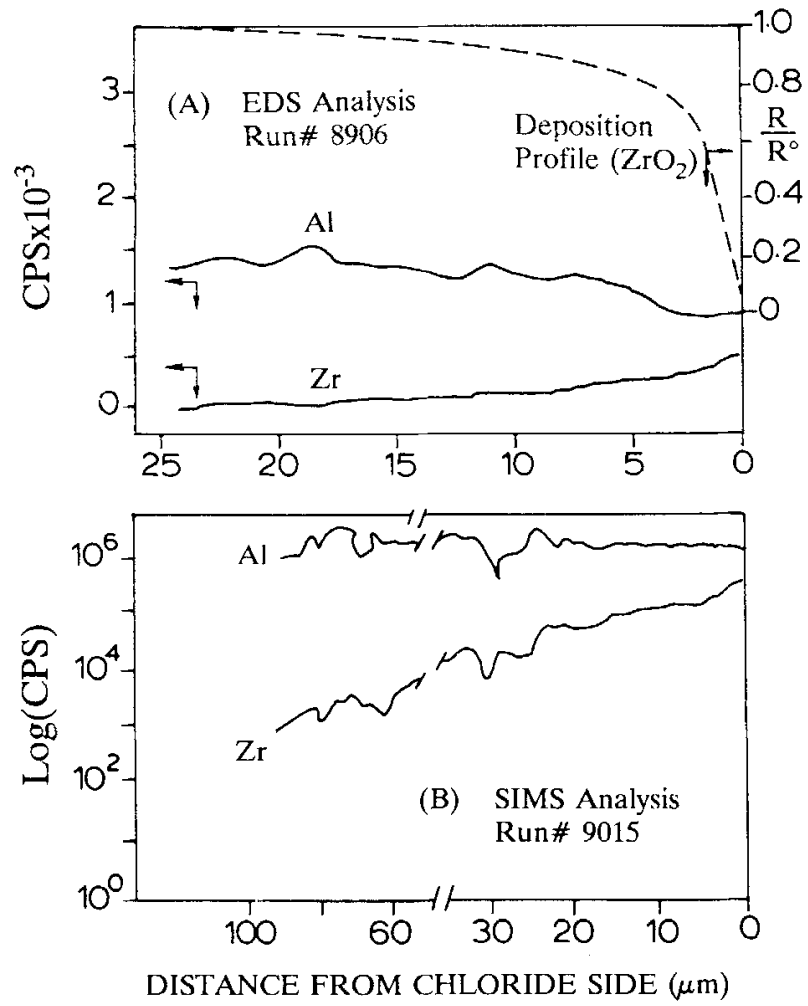

Figure 4. Distribution of zirconia across a coarse pore substrate measured by EDS (A) and SIMS (B).

The dashed curve is the deposition profile of $\mathrm{ZrO}_{2}$ converted from the EDS result based on the cylindrical pore model.

of zirconia on the grain surface deeper into a substrate could be determined by SIMS, but not by EDS. But if we define the penetration depth as the distance between the substrate edge (at the chloride side) and the location inside the substrate at which the determined amount of $\mathrm{Zr}$ is about $1 / 10$ of that at the edge, both EDS and SIMS measurements give similar values of the penetration depth $(10-20 \mu \mathrm{m})$. Most studied substrates after the deposition of $\mathrm{ZrO}_{2}$ exhibit this kind of deposit dis-

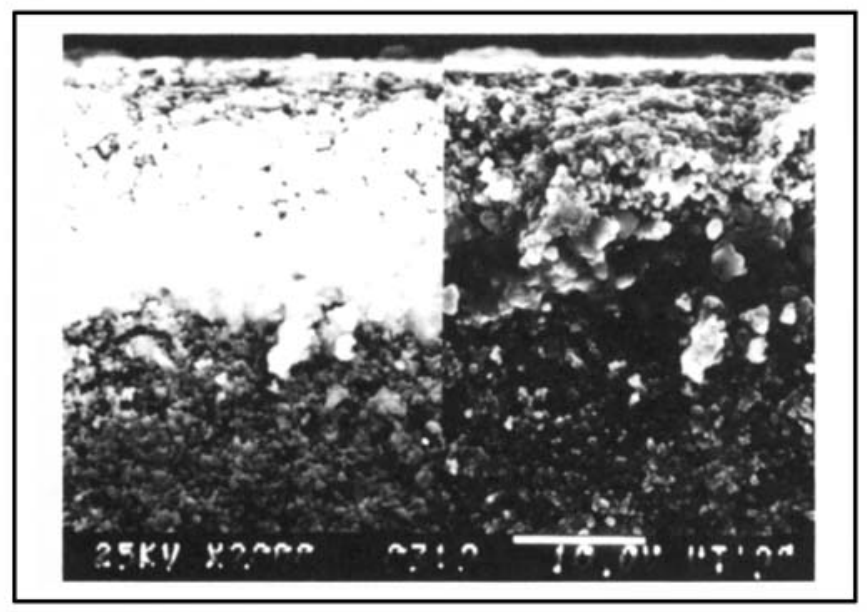

Figure 5. SEM photo showing a different deposit distribution across a coarse pore substrate in comparison with Figure 3.

Bar shown in the SEM is $10 \mu \mathrm{m}$. tribution. The experimental deposition profile converted from EDS result based on the cylindrical pore model is also shown in Figure 4a.

Based on the earlier modeling results with the boundary conditions of zero concentration, a reaction mechanism of zero reaction order with respect to water vapor and first (or higher) reaction order with respect to $\mathrm{ZrCl}_{4}$ was suggested to explain these experimental findings (Carolan and Michaels, 1987; Lin et al., 1989b). The more recent theoretical analysis using the boundary conditions of zero concentration derivative (Lin and Burggraaf, 1991b) shows that to obtain this kind of deposition profiles the reaction order with respect to water vapor is not necessarily zero. Simulated deposition profiles for both cases of different reaction order with respect to the two reactants (Lin et al., 1989b; Lin and Burggraaf, 1991b) agree with experimental deposition profiles. However, the reaction mechanism of zero reaction order with respect to water vapor cannot explain more experimental results reported below. To give an example, Figure 5 shows a SEM photo for a particular deposition result on a coarse pore substrate with a deposition profile different from most of the deposition runs. For this sample which was deposited at a slightly higher total pressure ( 3.5 mbar), the maximum deposition location, as seen from the SEM photo, is about $20 \mu \mathrm{m}$ inside the substrate from the chloride side. The precise cause for this kind of deposition profile is not clear at this moment. Nevertheless, this kind of deposition profile should not occur for a temperature-gradientless deposition of zirconia with a zero reaction order with respect to water vapor. The reaction mechanism with a nonzero reaction order with respect to water vapor is believed to be more suitable to describe the reaction between $\mathrm{ZrCl}_{4}$ and $\mathrm{H}_{2} \mathrm{O}$ in substrate pores. This will be substantiated by the experimental results presented next.

\section{Effects of reactant concentrations}

To investigate the effects of the bulk concentration of water vapor and $\mathrm{ZrCl}_{4}$ vapor on the deposition results, deposition experiments were performed on the coarse pore substrates with different water vapor concentration and sublimation temperature for $\mathrm{ZrCl}_{4}$ sublimation bed. To study the effects of water vapor concentration, a mixture of water vapor and hydrogen (as carrier gas) with different water vapor/hydrogen ratio was used as the oxygen source reactant. Helium permeability for a substrate before deposition and after 30-min deposition was measured to indicate the pore-narrowing rate. It is found that for the oxygen source reactant with a water vapor concentration of $1.15 \times 10^{-8}, 0.35 \times 10^{-8}$ and $0.21 \times 10^{-8} \mathrm{~mol} / \mathrm{mL}$, the He permeability ratios for a substrate after $30-\mathrm{min}$ deposition to the same substrate before deposition were $0.04,0.67$, and 0.77 , respectively. Furthermore, the penetration depth of zirconia for the case with the lowest water vapor concentration is much deeper than the case with the highest water vapor concentration. These results strongly suggest that water vapor concentration is very important in affecting the pore-narrowing rate and the width of the deposition zone. This is possibly only with a CVD reaction of a nonzero reaction order with respect to water vapor.

The deposition results with different $\mathrm{ZrCl}_{4}$ sublimation temperatures show a general trend that exhibits a decrease of penetration depth and pore-narrowing rate with decreasing 
Table 3. Effect of Sublimation Bed Temperatures on the PoreNarrowing Rate in Membrane Substrates*

\begin{tabular}{cccc}
$\begin{array}{l}\text { Run } \\
\text { No. }\end{array}$ & $\begin{array}{c}T_{\mathrm{ZCl}_{4}} \\
\left({ }^{\circ} \mathrm{C}\right)\end{array}$ & $\begin{array}{l}T_{\mathrm{YC} l_{3}} \\
\left({ }^{\circ} \mathrm{C}\right)\end{array}$ & $\begin{array}{c}\text { Permeability } \\
\text { Ratio*** }\end{array}$ \\
\hline 9031 & 140 & 613 & 0 \\
9033 & 120 & 550 & 0.03 \\
9034 & 100 & 480 & 0.25 \\
9035 & 80 & 430 & 0.83 \\
\hline
\end{tabular}

* Deposition temperature $=800^{\circ} \mathrm{C}$

* Ratio of He permeability after 20-min deposition to that before deposition for the same membrane substrate.

sublimation bed temperature for $\mathrm{ZrCl}_{4}\left(T_{\mathrm{ZrCl}_{4}}\right)$ (decreasing the metal chloride vapor concentration, $C_{m}^{o}$ ). For example, values of $L_{B}$ (penetration depth) of about 4,10 and $15 \mu \mathrm{m}$ and poreclosure time of 45,35 and $25 \mathrm{~min}$ were found at $T_{\mathrm{ZrCl}_{4}}=140$, 160 and $180^{\circ} \mathrm{C}$, respectively, for the deposition of zirconia in the coarse pore substrates. The effects of $\mathrm{ZrCl}_{4}$ vapor concentration on membrane substrates are found to be the same. The ratio of He permeability after deposition to that before deposition on the membrane substrates with different sublimation temperatures is summarized in Table 3 . It is obvious that a higher $\mathrm{ZrCl}_{4}$ sublimation bed temperature (higher $\mathrm{ZrCl}_{4}$ vapor concentration) results in a larger pore-narrowing rate (or shorter pore-closure time). The theoretical analysis suggests that an increase in the ratio of $C_{\mathrm{ZrCl}_{4}}^{o} / C_{\mathrm{H}_{2} \mathrm{O}}^{o}$ may result in a wider deposition zone with a smaller pore-narrowing rate under the following conditions: (1) value of the modified Thiele modulus is large (narrow deposition zone); (2) the maximum deposition is located at the chloride side; and (3) CVD reaction mechanism is of nonzero reaction order with respect to water vapor. Experimental results are consistent with the theoretical analysis.

\section{Effects of different oxygen source reactants}

Depositions of $\mathrm{ZrO}_{2}$ on the coarse pore substrates with two different oxygen source reactants, (A) pure oxygen (or dry air) and (B) water vapor carried by air (or by hydrogen), were compared under the same conditions. After 15-min deposition, no observable change in the Ar permeability was found for the substrate with reactant $A$ but the Ar permeability decreased by $20-40 \%$ with reactant B. The Ar permeability was found to decrease by about $5-10 \%$ after 2 -h deposition with reactant A. These results obviously indicate that the pore-narrowing rate with water vapor is higher than that with pure oxygen. This can be explained by the following two possibilities:

1. CVD Reaction Mechanism. Since in the present experiments the CVD reaction takes place in the Knudsen diffusion

Table 4. Effects of the Top-Layer Pore Dimension of Membrane Substrates on the Deposition Results

\begin{tabular}{|c|c|c|c|c|c|}
\hline \multirow{2}{*}{$\begin{array}{l}\text { Sample } \\
\text { No. }\end{array}$} & \multirow{2}{*}{$\begin{array}{l}\text { Run } \\
\text { No. }\end{array}$} & \multicolumn{2}{|c|}{ Top Layer } & \multirow{2}{*}{$\begin{array}{l}\text { Deposition } \\
\text { Time (min) }\end{array}$} & \multirow{2}{*}{$\begin{array}{l}\text { Permeability } \\
\text { Ratio* }\end{array}$} \\
\hline & & $\overline{R^{\circ}(\mathrm{nm})}$ & $L(\mu \mathrm{m})$ & & \\
\hline 1 & 9031 & 10 & 3 & 20 & 0 \\
\hline 2 & 9067 & 10 & 6 & 20 & 0.63 \\
\hline 3 & 9073 & 10 & 6 & 20 & 0.62 \\
\hline 4 & 9066 & 5 & 6 & 20 & 0.94 \\
\hline 5 & 9065 & 5 & 6 & 30 & 0.60 \\
\hline
\end{tabular}

- Ratio of He permeability after 20 - or 30 -min deposition to that before deposition for the same substrate. regime in the porous substrates (that is, high temperature, low pressure, and small pore size), the CVD reaction is more likely to proceed via adsorption of the oxygen and metal source reactants, followed by the surface reaction between the adsorbed species to form solid deposit. This is called the Langmuir-Hinshelwood mechanism (Butt, 1980). Under such a circumstance, the "lumped" reaction rate $K$ is proportional to $\left(K_{\mathrm{MCI}} K_{\mathrm{OSR}} K_{s}\right)$ (for the first reaction order with respect to both metal chloride vapor and oxygen source reactant, where $K_{\mathrm{MCl}}$ and $K_{\mathrm{OSR}}$, respectively, are the absorption equilibrium constants for metal chloride vapor and oxygen source reactant). Value of $K_{s}$ as well as of $K_{\mathrm{MCl}}$ should be similar in these two cases of different oxygen source reactants. However, because of the polar (hydrophilic) nature of the substrate (alumina) internal surface, $K_{\mathrm{OSR}}$ for water vapor can be much larger than that for oxygen, resulting in a larger deposition rate for water vapor.

2. Water Vapor (or Oxygen) Concentration-Dependent Reaction Mechanism. The difference in deposition results of these two types of reactants may be due to that in the diffusivity ratio $\lambda_{M}$ for water and oxygen. In Knudsen diffusion regime, $\lambda_{M}$ is 3.6 for water vapor and 2.7 for oxygen (with respect to that for $\mathrm{ZrCl}_{4}$ vapor). Compared to the case with water vapor, the smaller diffusivity ratio for oxygen may result in a wider deposition zone and a slower pore-narrowing rate, especially in the case with a large modified Thiele modulus.

\section{Effects of substrate pore dimension}

The initial Ar permeability (before deposition) and the poreclosure time for the three types of substrate with different pore dimensions are also given in Table 1 . The shorter pore-closure time for the membrane substrate is due mainly to the much smaller pore size of its top layer compared with the coarse pore substrate. Comparing coarse pore and composite substrates, one finds that the pore-closure time for the composite substrate with a larger pore size of the top layer is shorter than that of coarse pore substrate. This is not possible for a reaction with a zero reaction order with respect to water vapor, because for such a case the pore-closure time is proportional to the substrate pore size, as shown by Eq. 7. For the case of a reaction with a nonzero reaction order with respect to water vapor and $\mathrm{ZrCl}_{4}$ vapor, a substrate with a smaller value of $L / D_{0}^{\circ}$ (smaller diffusion resistance or larger initial Ar permeability) can have a larger pore-narrowing rate. Therefore, the pore-narrowing rate on the composite substrate can be larger than that on the coarse pore substrate.

The effects of the pore dimension on the deposition results are more evident on the membrane substrates with different top-layer pore dimensions, as shown in Table 4. Comparing the first sample with the second (or third) sample, all with the same top-layer pore size but different top-layer thickness, the much larger pore-narrowing rate (the smaller value of the permeability ratio) for the first sample is obviously due to its smaller top-layer thickness (smaller pore diffusion resistance). Between the second (or the third) sample and the forth (or fifth) sample, with the same top layer thickness but different pore size, the pore-narrowing rate is larger for the samples with a larger pore size. These data show that the pore-narrowing rate depends strongly on the substrate pore dimension, partly because of the CVD reaction mechanism with a nonzero reaction order with respect to water vapor. 
Table 5. Effects of Deposition Temperature on the Deposition Results in Membrane and Coarse Pore Substrates

\begin{tabular}{|c|c|c|c|}
\hline $\begin{array}{l}\text { Run } \\
\text { No. }\end{array}$ & $\begin{array}{l}T_{\text {dep }} \\
\left({ }^{\circ} \mathrm{C}\right)\end{array}$ & $\begin{array}{c}\text { Permeability } \\
\text { Ratio* }\end{array}$ & $\frac{L_{B}}{(\mu \mathrm{m})^{+}}$ \\
\hline & \multicolumn{3}{|c|}{ Membrane Substrates ${ }^{* *}$} \\
\hline 9,031 & 800 & 0.10 & -0.3 \\
\hline 9,024 & 1,000 & $>0.86$ & $\sim 0.5$ \\
\hline & \multicolumn{3}{|c|}{ Coarse Pore Substrates } \\
\hline 9,007 & 700 & 0.5 & 3 \\
\hline 9,006 & 800 & 0.51 & 5 \\
\hline 9,004 & 850 & 0.42 & 10 \\
\hline 9,005 & 950 & 0.67 & 10 \\
\hline 9,002 & 1,000 & 0.97 & 15 \\
\hline
\end{tabular}

- Ratio of permeability after deposition to that before deposition for the same substrate. Deposition time: $5 \mathrm{~min}$ for the membrane substrates (He as permeating gas) and $10 \mathrm{~min}$ for the coarse pore substrates ( $\mathrm{Ar}$ as permeating gas).

** Top-layer pore dimension $L=3 \mu \mathrm{m}, R^{\circ}=10 \mathrm{~nm} ; T_{2 \mathrm{rCl}}=140^{\circ} \mathrm{C}$.

+ Estimated from SEM back-scattered electron images.

\section{Effects of deposition temperature}

The penetration depth $\left(L_{B}\right)$ (the width of deposition zone) and the permeability ratios on the membrane substrates and coarse pore substrates at different deposition temperature are summarized in Table 5. The width of deposition zone increases and the pore-narrowing rate decreases with increasing deposition temperature. According to the theoretical analysis, these experimental results indicate a decrease in the modified Thiele modulus $\Phi$ with increasing deposition temperature for the studied CVD reaction systems. Since the diffusivity in Knudsen regime increases only slightly with temperature in the studied temperature range, these results suggest that the "apparent" reaction rate constant $K$ decreases with increasing deposition temperature. This is possible when the Langmuir-Hinshelwood reaction mechanism is involved in the CVD reaction on the internal pore surface of the porous substrates. Since the adsorption equilibrium constants decrease and $K_{s}$ increases with the temperature, the "apparent" reaction rate constant $K$ may decrease with increasing temperature if the heats of adsorption for the reactants are larger than the activation energy of the surface reaction.

\section{Verification on pore-size reduction}

In the theoretical analysis using the cylindrical pore model, the uniform pore-size distribution for a substrate was assumed, and therefore the deposition of the solid in the internal pore surface would surely reduce the average pore size. In practice, however, a reduction in gas permeability after deposition does not ensure an average pore-size decrease because any substrate
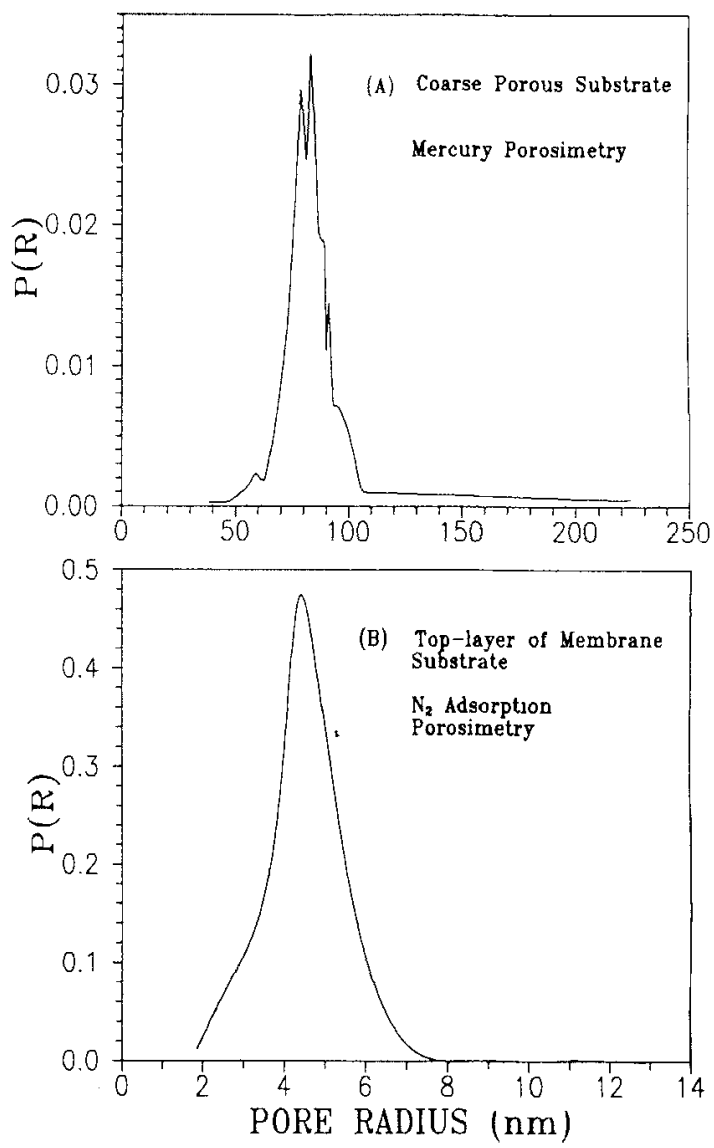

Figure 6. Normalized pore-size distributions of the coarse pore substrate and the top-layer of the membrane substrate.

has a pore-size distribution. Since the gas permeability is related to the average pore size and the porosity, as shown by Eqs. $8-10$, a reduction in the gas permeability may also mean a decrease in the porosity of a substrate after deposition. As the deposited substrates are a complex composite systems, direct measurement of the pore-size distribution of the deposited part of a substrate is rather difficult. To roughly check whether the deposition of zirconia in the substrate pores results in a poresize reduction or just the porosity reduction, He permeability at different average pressure was measured for a coarse pore substrate and a membrane substrate before and after deposition. The coefficients $\alpha^{\prime}$ and $\beta^{\prime}$ are regressed from the $\mathrm{He}$ permeability data of $(F / L)$ vs. $P_{\text {av }}$, and the results as well as the ratio of $\beta^{\prime} / \alpha^{\prime}$ are listed in Table 6 .

Table 6. Verification of Pore-Size Reduction by He Permeability*

\begin{tabular}{|c|c|c|c|c|}
\hline \multirow[t]{2}{*}{$\begin{array}{l}\text { Substrate, Run No. \& } \\
\text { Deposition Time }\end{array}$} & \multicolumn{2}{|c|}{$\begin{array}{c}\text { Coarse Pore, Run No. } 9076 \\
10 \text {-min Deposition }\end{array}$} & \multicolumn{2}{|c|}{$\begin{array}{c}\text { Membrane (Top Layer } L=6 \mu \mathrm{m}, \\
R^{\circ}=10 \mathrm{~nm} \text { ), Run No. } 9073 \\
20-\text { min Deposition }\end{array}$} \\
\hline & $\begin{array}{l}\text { Before } \\
\text { CVD }\end{array}$ & $\begin{array}{l}\text { After } \\
\text { CVD }\end{array}$ & $\begin{array}{l}\text { Before } \\
\text { CVD }\end{array}$ & $\begin{array}{l}\text { After } \\
\text { CVD }\end{array}$ \\
\hline $\begin{array}{l}\alpha^{\prime} \times 10^{6}\left(\mathrm{~mol} / \mathrm{m}^{2} \cdot \mathrm{s} \cdot \mathrm{Pa}\right) \\
\beta^{\prime} \times 10^{12}\left(\mathrm{~mol} / \mathrm{m}^{2} \cdot \mathrm{s} \cdot \mathrm{Pa}^{2}\right) \\
\beta^{\prime} / \alpha^{\prime} \times 10^{7}\left(\mathrm{~Pa}^{-1}\right)\end{array}$ & $\begin{array}{l}3.62 \\
2.58 \\
7.13\end{array}$ & $\begin{array}{l}2.91 \\
2.09 \\
7.18\end{array}$ & $\begin{array}{l}2.60 \\
2.14 \\
8.22\end{array}$ & $\begin{array}{l}1.61 \\
1.12 \\
6.95\end{array}$ \\
\hline
\end{tabular}

* Deposition conditions are the same as in Table 2 , but with $T_{\text {dep }}=800^{\circ} \mathrm{C}$ and $T_{\mathrm{ZrCl}_{4}}=140^{\circ} \mathrm{C}$ for the deposition on membrane substrates. 
As shown by Eqs. 9 and 10 , the ratio of $\left(\beta^{\prime} / \alpha^{\prime}\right)$ is proportional to the pore size. The value of $\left(\beta^{\prime} / \alpha^{\prime}\right)$ for the coarse pore substrate after deposition is slightly larger than that before deposition, indicating an increase in the average pore size after deposition for the coarse pore substrates. It has been experimentally verified that the pores of the coarse pore substrate itself did not grow under the deposition conditions $\left(1,000^{\circ} \mathrm{C}\right.$, $3-5 \mathrm{~h})$. Therefore, the increase in $\left(\beta^{\prime} / \alpha^{\prime}\right)$ after deposition is due to the increase in the average pore size in the deposition zone of the coarse pore substrate. Because the coarse pore substrate has relatively broader pore-size distribution with a small amount of much larger pores (pore radius from 110 to $220 \mathrm{~nm}$ ), as shown in Figure $6 \mathrm{~A}$, it is possible that the large number of small pores are plugged first by the deposit, resulting in an increase in the average pore size. For the membrane substrate, the value of $\left(\beta^{\prime} / \alpha^{\prime}\right)$ decreases after deposition, showing a possible reduction of the average pore size of the top layer of the membrane substrate. This is related to the fact that the membrane substrate has a top layer with a more uniform pore-size distribution, as shown in Figure 6B. This kind of change in $\left(\beta^{\prime} / \alpha^{\prime}\right)$ was found for all the membrane substrates studied. It should be pointed out that the permeability coefficient data in Table 6 are the averaged values for whole substrate, not for the top layer of the deposition zone of a substrate.

\section{Conclusions}

Yttria-doped zirconia was deposited in the pores of various types of substrate from the CVD reaction between water vapor and $\mathrm{ZrCl}_{4}$ (and $\mathrm{YCl}_{3}$ ) vapor. For the two-layer membrane substrates, the deposit was present mainly in the top layer of the substrate. The gas permeation data indicate a possible reduction of the mean pore size of membrane top layer by depositing solid oxide in the membrane pores.

Consistent experimental and theoretical results suggest a reaction mechanism for the studied CVD reaction in porous substrates which is water-vapor-concentration-dependent. From the stoichiometry coefficients of the studied CVD reaction, a reaction mechanism with first order with respect to $\mathrm{ZrCl}_{4}$ vapor and at least first order with respect to water vapor can be proposed. This mechanism can explain most of the experimental findings reported in this article. Furthermore, it is found that a higher deposition temperature results in a slower pore-narrowing rate and wider deposition zone, suggesting a Langmuir-Hinshelwood reaction mechanism in which equilibrium of adsorption of water vapor and/or $\mathrm{ZrCl}_{4}$ vapor on substrate pore surface plays a major role in affecting the deposition rate.

A systematic experimental study on the effects of different parameters, with the theoretical analysis, resulted in the following conclusions for the studied CVD process:

- The maximum deposition location was found at the substrate surface exposed to the metal chloride vapor. Contrary to what was suggested in the previous studies, this is not due to a reaction mechanism of zero reaction order with respect to water vapor, but is caused by the fact that the intrapore diffusivity and the bulk concentration for water vapor are larger than those for $\mathrm{ZrCl}_{4}$ vapor.

- The pore-narrowing rate with water as the oxygen source reactant was found to be much larger than that with oxygen due to the difference in the intrapore diffusivity or the CVD reaction rate.
- Narrow deposition zones were found for the deposition of $\mathrm{ZrO}_{2}$ in the porous substrates due to a large value of modified Thiele modulus (a large reaction rate constant) for the studied CVD process.

- The pore closure time depended not only on the substrate pore size but also on other parameters such as substrate thickness, due to the water-vapor-concentration-dependent reaction mechanism.

- An increase in the bulk-phase concentration of $\mathrm{ZrCl}_{4}$ or water vapor raises the pore-narrowing rate. However, a larger $\mathrm{ZrCl}_{4}$ concentration or smaller water vapor concentration resulted in a wider deposition zone for the studied CVD process.

\section{Acknowledgment}

This investigation was supported by the Dutch Ministry of Economical Affairs grant, IOP Technical Ceramics No. 87 A045. The authors would like to thank P. Fransen and J. Meijerink for their assistance in performing experiments.

\section{Notation}

$C_{m}^{0}=$ concentration of metal source reactant in the chloride chamber, $\mathrm{mol} / \mathrm{cm}^{3}$

$C_{0}^{o}=$ concentration of oxygen source reactant in the oxygen chamber, $\mathrm{mol} / \mathrm{cm}^{3}$

$D_{m}^{o}=$ effective intrapore diffusivity for metal source reactant, $\mathrm{cm}^{2} / \mathrm{s}$

$D_{\mathrm{O}}^{o}=$ effective intrapore diffusivity for oxygen source reactant, $\mathrm{cm}^{2} / \mathrm{s}$

$F=$ permeability, $\mathrm{mol} \cdot \mathrm{m} / \mathrm{s} \cdot \mathrm{Pa}$

$K=$ apparent reaction rate constant, $\mathrm{cm}^{3 N+3 M-2} / \mathrm{mol}^{N+M-1} \cdot \mathrm{s}$

$K_{\mathrm{H}_{2} \mathrm{O}}=$ adsorption equilibrium constant for water vapor

$K_{\mathrm{ZrCl}}=$ adsorption equilibrium constant for $\mathrm{ZrCl}_{4}$ vapor

$K_{s}=$ surface reaction rate constant, $\mathrm{cm}^{3 N+3 M-2} / \mathrm{mol}^{N+M-1} \cdot \mathrm{s}$

$L=$ thickness of substrate disk, $\mathrm{cm}$

$L_{B}=$ width of deposition zone (or penetration depth of deposit), $\mu \mathrm{m}$

$M=$ reaction order with respect to water vapor

$M_{g}=$ molecular weight of permeating gas, $\mathrm{g} / \mathrm{mol}$

$N=$ reaction order with respect to metal chloride vapor

$q=$ maximum pore narrowing rate, $\mathrm{cm} / \mathrm{s}$

$P_{\mathrm{av}}=$ average total pressure across a substrate disk, $\mathrm{Pa}$

$P_{h}=$ upstream pressure during permeation measurements, $\mathrm{Pa}$

$P_{l}=$ downstream pressure during permeation measurements, $\mathrm{Pa}$

$P_{t 0}=$ total pressure in the oxygen chamber, $\mathrm{Pa}$

$P_{t M}=$ total pressure in the metal chloride chamber, $\mathrm{Pa}$

$Q=$ mass flow rate through a membrane in permeation measurements, $\mathrm{mol} / \mathrm{s}$

$S=$ cross-sectional area of a membrane in permeation measurements, $\mathrm{cm}^{2}$

$R=$ local radius of substate pore, $\mu \mathrm{m}$

$R^{o}=$ average radius of substrate pore before deposition, $\mu \mathrm{m}$

$\boldsymbol{R}_{\boldsymbol{g}}=$ gas constant, $\mathrm{J} / \mathrm{mol} \cdot \mathrm{K}$

$T_{\text {dep }}=$ deposition temperature, ${ }^{\circ} \mathrm{C}$

$T_{\mathrm{ZrCl}}=$ sublimation bed temperature for $\mathrm{ZrCl}_{4},{ }^{\circ} \mathrm{C}$

$t=$ deposition time, $\mathrm{s}$ or $\min$

$t_{p c}=$ pore-closure time, $\mathrm{s}$ or $\mathrm{min}$

$Z=$ axial position of a substrate pore, $\mathrm{cm}$

\section{Greek letters}
$\alpha=$ pressure drop coefficient, Eq. 4
$\alpha^{\prime}=$ permeability coefficient contributed by the Knudsen diffu- sion, $\mathrm{mol} / \mathrm{m}^{2} \mathrm{~s} \cdot \mathrm{Pa}$
$\beta=$ ratio of bulk phase concentration of $\mathrm{ZrCl}_{4}$ vapor to that of water vapor
$\beta^{\prime}=$ permeability coefficient contributed by the viscous flow, $\mathrm{mol} / \mathrm{m}^{2} \cdot \mathrm{s} \cdot \mathrm{Pa}^{2}$
$\epsilon=$ average porosity of substrate 
$\lambda_{M}=$ ratio of effective diffusivity of $\mathrm{ZrCl}_{4}$ vapor to that of water vapor in substrate pores

$\lambda_{v}=$ ratio of viscous flow velocity to diffusivity, Eq. 5

$\tau=$ tortuosity factor of substrate

$\mu=$ viscosity of carrier gas

$\Phi=$ modified Thiele modulus, Eq. 1

\section{Literature Cited}

Burggraaf, A. J., and K. Keizer, "Synthesis of Inorganic Membranes," Inorganic Membranes: Synthesis, Characteristics and Ap plications, R. R. Bhave, ed., Chap. 2, van. Nostrand Reinhold, New York (1991).

Butt, J. B., Reaction Kinetics and Reactor Design, Chap. 2, PrenticeHall, Englewood Cliffs, NJ (1980).

Carolan, M., and J. N. Michaels, "Chemical Vapor Deposition of Yttria-Stabilized Zirconia on Porous Substates," Solid State Ionics, 25, 207 (1987).

Carolan, M., and J. N. Michaels, "Growth Rates and Mechanism of Electrochemical Vapor-Deposited Yttria-Stabilized Zirconia Films," Solid State Ionics, 37, 189 (1990).

de Haart, L. G. J., Y. S. Lin, K. J. de Vries, and A. J. Burggraaf, "Modified CVD of Nanoscale Structure in and EVD of Thin Layers on Porous Ceramic Membranes," J. Eur. Ceram. Soc., 8, 59 (1991).

Gavalas, G. R., C. E. Migiris, and S. W. Nam, "Deposition of $\mathrm{H}_{2}$ Permselective $\mathrm{SiO}_{2}$ Films," Chem. Eng. Sci., 44, 1829 (1989).

Hsieh, H. P., "Inorganic Membranes," AIChE Symp. Ser., 84(261), 1 (1988).

Isenburg, A. O., "Growth of Refractory Oxide Layers by Electrochemical Vapor Deposition (EVD) at Elevated Temperatures," Proc. Symp. Electrode Materials, Processes for Energy Conversion and Storage, 77(6), 572 (1977).

Keizer, K., R. J. R. Uhlhorn, R. J. v. Vuren, and A. J. Burggraaf, "Gas Separation Mechanisms in Microporous Modified $\gamma-\mathrm{Al}_{2} \mathrm{O}_{3}$ Membranes," J. Membr. Sci., 39, 258 (1988).
Lin, Y. S., L. G. J. de Haart, K. J. de Vries, and A. J. Burggraaf, "Modification of Ceramic Membranes by CVD and EVD for Gas Separation, Catalysis and SOFC Application," Euro-Ceramics: 3. Engineering Ceramics, p. 3.590, G. de With et al., eds., Elsevier, London (1989a).

Lin, Y. S., K. J. de Vries, and A. J. Burggraaf, "CVD Modification of Ceramic Membranes: Simulation and Preliminary Results," $J$. de Phys. Colloq., 50(5), 861 (1989b).

Lin, Y. S., P. Fransen, K. J. de Vries, and A. J. Burggraaf, "Experimental Study on CVD Modification of Ceramic Membranes," Proc. Int. Conf. CVD, p. 539, K. E. Spear, ed., Electrochemical Soc., Pennington NJ (1990a).

Lin, Y. S., L. G. J. de Haart, K. J. de Vries, and A. J. Burggraaf, "A Kinetic Study on the Electrochemical Vapor Deposition of Solid Oxide Films on Porous Substrates," J. Electrochem. Soc., 137, 3960 (1990b).

Lin, Y. S., and A. J. Burggraaf, "Preparation and Characterization of High-Temperature Thermally Stable Alumina Composite Membrane," J. Amer. Ceram. Soc., 74, 219 (1991a).

Lin, Y. S., and A. J. Burggraaf, "Modeling and Analysis of CVD Processes in Porous Media for Ceramic Composite Preparation," Chem. Eng. Sci., 46, 3067 (1991b).

Nam, S. W., and G. R. Gavalas, "Stability of $\mathrm{H}_{2}$-Permselective $\mathrm{SiO}_{2}$ Films Formed by Chemical Vapor Deposition," AIChE Symp. Ser., 268, 68 (1989).

Okubo, T., and H. Inoue, "Introduction of Specific Gas Selectivity to Porous Glass Membranes by Treatment with Tetraethoxysilane," J. Membr. Sci., 42, 109 (1989).

Pal, U. B., and S. C. Singhal, "Electrochemical Vapor Deposition of Yttria-Stabilized Zirconia Films," J. Electrochem. Soc., 137, 2937 (1990).

Manuscript received July 8, 1991, and revision received Jan, 28, 1992. 